\title{
FRACTURES OF THE MALAR-ZYGOMATIC COMPOUND
}

\author{
By J. B. Prendiville, F.R.C.S.I.
}

From the Plastic and Maxillo-Facial Unit, Wythenshawe Hospital, Manchester

Fractures of the malar-zygomatic compound have in recent years emerged from relative obscurity and become one of the better known fractures seen in casualty departments and maxillofacial units. During the period from January 1950 to August 195 I, 107 cases were treated in this unit at the Wythenshawe Hospital and an analysis of these cases is given in this paper. More car and motor-cycle accidents have been given as the cause of the apparent increase in the numbers now seen, but our records tend to show that many are still due to brawls, flying missiles and falls. A better knowledge in the diagnosis of this type of injury and the ever-increasing use of $\mathrm{X}$-rays may be the most important factors; 72 per cent. of this series were adult males, 27 per cent. were females and one was a boy of four.

\section{Anatomy}

The malar-zygomatic compound is formed by the zygoma, its frontal and maxillary processes and the zygomatic arch. The zygoma is a quadrilateral-shaped bone which forms the prominence of the cheek in the upper and outer quadrant of the face. It articulates posteriorly by its temporal process with the zygomatic process of the temporal bone forming the zygomatic arch. Anteroinferiorly it articulates with the zygomatic process of the maxilla and is separated from the maxillary antrum by a thin triangular plate of bone. Its antero-superior border forms a considerable part of the lower and outer quadrant of the orbital margin and at the upper end of this border it articulates with the frontal bone. The zygomatic arch overlies the temporal fossa, the temporalis muscle and coronoid process of the mandible. Along the upper border of the arch is attached the temporal fascia and below it gives origin to the masseter muscle.

\section{Mechanism of Injury}

In all cases a direct impact acting on the solid zygoma and forcing it against the resistance of the skull, fractured the processes of the zygoma at their articulations. This impact may be due to the head hitting a solid object or being hit by an external force such as a fist or a flying missile. The following is a list of the causes:

Road accidents ... ...

. 42

$\begin{array}{lllllll}\text { Brawls } & . & \ldots & \ldots & \ldots & & \end{array}$

$\begin{array}{lllllll}\text { Falls } & \ldots & \ldots & \ldots & \ldots & \ldots & 20\end{array}$

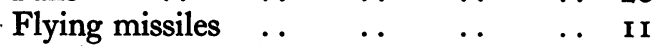

Head-to-head collisions (football) $\quad$. 5

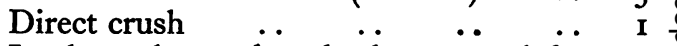

In those due to brawls the external force was usually a fist or a kick, but a few were not certaifo on this point. In those due to falls, cycle and motor-car accidents, the head was the moving force coming into contact with the ground or windscreen of the car. Six of the flying missiles were cricket balls.

\section{Symptoms}

In the first week after injury, pain and swelling of the cheek were the most constant complaints. They were almost consistently accompanied by numbness of the cheek, nasal bleeding, limitation of jaw movements and diplopia in many. Bony deformity was not usually noticed by the patient at this stage. Of the late cases seen, deformity, limitation of jaw movements and visual disturbances-such as tiredness and blurring of vision due to diplopia-were the symptoms for which the patient sought treatment.

\section{Findings on Examination}

Swelling of the cheek due to oedema, ecchymosis and surgical emphysema from the antrum was almost always present. Anaesthesia over the distribution of the infra-orbital nerve and limitation of jaw movements were frequently found. Diplopia, present in 18 per cent., was best demonstrated by holding the head with the left hand whilst the patient followed the right index finger 
to the extremities of eye movements; in most cases this was due to swelling which disappeared when this subsided and the fracture had been reduced, but in the later cases with deformity it was accounted for by the depression of the floor of the orbit with downward and outward subluxation of the eye. External palpation helped to reveal displacement of the bone, especially along the lower margin of the orbit where a step was frequently noted. Inside the cheek the lower margin of the bone and arch were also palpated. Deformity, when present, was much more obvious and disfiguring in the late cases and always accompanied by anaesthesia in the distribution of the infra-orbital nerve. Limitation of jaw movements was due to swelling and trismus in the majority, but in a few was accounted for by infringement of the fracture on the temporalis muscle and the coronoid process of the mandible and in one to a loose fragment of bone.

\section{Lesion as shown on X-ray}

The fracture lines were usually of a uniform type running through the fronto-zygomatic and tempero-zygomatic articulations and just below the zygomatico-maxillary suture line, at this point involving the maxillary antrum. The displacement was a downward and inward rotation of the bone which was impacted into the antrum. The latter was shown to be reduced in size and opaque due to haemorrhage. In ro per cent. of the fractures there was considerable comminution, especially along the wall of the antrum. In only five cases the zygomatic arch alone was fractured. In these the arch was fractured in two or more places with depression of the loose fragment. We used the $30^{\circ}$ occipitomental view in our X-ray films (Clark, 1949).

\section{Treatment}

\section{(1) Conservative}

In 25 of the cases there was no significant depression, jaw movements were full and there was no disturbance of vision. No treatment was required and all made an uneventful recovery.

\section{(2) Simple Elevation of the Malar}

This was the treatment of choice in all early cases of displacement which were stable on reduction. It was successfully carried out even up to six weeks after the accident.

Technique. The hair was shaved over the temporal region. Under general anaesthetic a transverse incision $I$ in. long was made through the scalp and temporal fascia about $I \frac{1}{2}$ in. above the zygomatic arch, in front of the superficial temporal vessels and within the hair line. A Howarth's blunt dissector was passed downwards beneath the temporal fascia and on the temporaling muscle to the under-surface of the malar to form a plane of cleavage. This was withdrawn and the malar elevator introduced along the same plane and hooked beneath the body of the bone and its maxillary process. The malar was then elevate $\bar{\phi}$ and rotated upwards by a strong levering action? Reduction was guided by the fingers of the lef hand and the bone felt to crunch into position of suddenly give way as it was disimpacted. Th $\mathrm{g}$ nose usually bleeds at this stage and the swelling of the face increased temporarily. In a similar manner fractures of the arch were elevated directly outwards. The wound was closed with thread sutures and this side marked with a cross of blue ink to warn the ward staff of the necessity avoiding pressure by lying on it. Check X-ray. was carried out in 24 hours.

\section{(3) Elevation of Malar combined with Immobilisation}

In six badly comminuted fractures which were not stable on reduction the antrum was exposed through the buccal sulcus above the canine tooth and the antrum packed with gauze soaked in Whitehead's varnish to maintain the reduces position. The pack was removed in three weeks and the antrum closed. One small antral fistglis was later found, but the patient did not complain of any disability from it.

In three cases the correct elevated positir could not be maintained by packing the antrumo This necessitated exposing the fronto-zygomatic fracture line and carrying out a direct wiring at the fracture line. This maintained an excellent position.

In one case a loose piece of the zygomatic arch? was lying in the temporal fossa and causect? difficulty in jaw movements. This was exploreds and removed.

\section{(4) Mal-united Malars with Symptoms}

There were four in this series and all com- 을 plained of diplopia. They were found to have downward and outward subluxation of the eyebalp due to depression of the floor of the orbit. Twos were corrected by placing a polythene mould beneath the eye through a direct exposure ands with an excellent immediate result. Unfor +0 tunately, one of these has just returned to us after eighteen months with an inflammatory reaction ${ }^{\omega}$ around the mould. The third was treated with a bone graft and bone chips from the ilium to build up the cheek and elevate the eye. Thes fourth was refractured by exposing the suture lines of the zygoma and the bone elevated. The latter was kept in position by fronto-zygomation wiring and an antral pack. 


\section{Results}

Eighty-two cases were traced and all except four were satisfied with their treatment and progressed satisfactorily. Of the four unsatisfactory results, three were fully elevated at operation but redisplaced subsequently. This was due to considerable comminution, with loss of bone and sepsis in one. The latter has since had a bone graft to build up her face and eye, but the other two do not regard their slight disfigurement as sufficient to warrant further operation. The fourth had a seven months' old depressed fracture and came to us complaining of diplopia. This was cured for eighteen months with a polythene mould, but this will have to be removed owing to the inflammatory reaction. Of those that progressed satisfactorily, one was very slightly overreduced. Infra-orbital anaesthesia was always slow in recovering and in 24 per cent. of those who originally complained of this there was still some numbness of the upper lip over six months from operation. Jaw movements were usually normal in an average of four to five weeks. In some patients diplopia was cured immediately after operation, but in many it remained until the swelling subsided.

\section{Summary}

Fractures of the malar-zygomatic compound have been described and an analysis given of 107 cases treated in this unit. We consider that more fractured malars are now seen because of their better recognition. The treatment of choice in simple depressed malars is elevation with a Bristow's elevator. In badly comminuted fractures which are not quite stable on reduction, antral packing and wiring of the fronto-zygomatic suture line is necessary. Established mal-union may be treated by refracture, polythene mould prosthesis or bone grafting.

\section{Acknowledgment}

I am indebted to Mr. A. H. R. Champion and Mr. A. McDowall for their encouragement and help in writing this paper and for kindly permitting me to use their cases.

\section{BIBLIOGRAPHY}

CARDWELL, E. P. (1949), F. Plast. and Reconstruct. Surg., 4, 235-25I.

CLARK, K. C. (1949), 'Positioning in Radiography,' 5th Edition, London: Heineminn. Page $x 90$.
GILLIES, H. D., KII..NER, T. P., and STONE, D. (1927), Brit. F. Surg., 14, 651-616.

MANSFIELD, O. 'T. (1948), Brit. F. Plast. Surg., I, 123-126.

TANZER, R. C. (1951), F. Plast. and Reconstruct. Surg., 7, 400-41 2

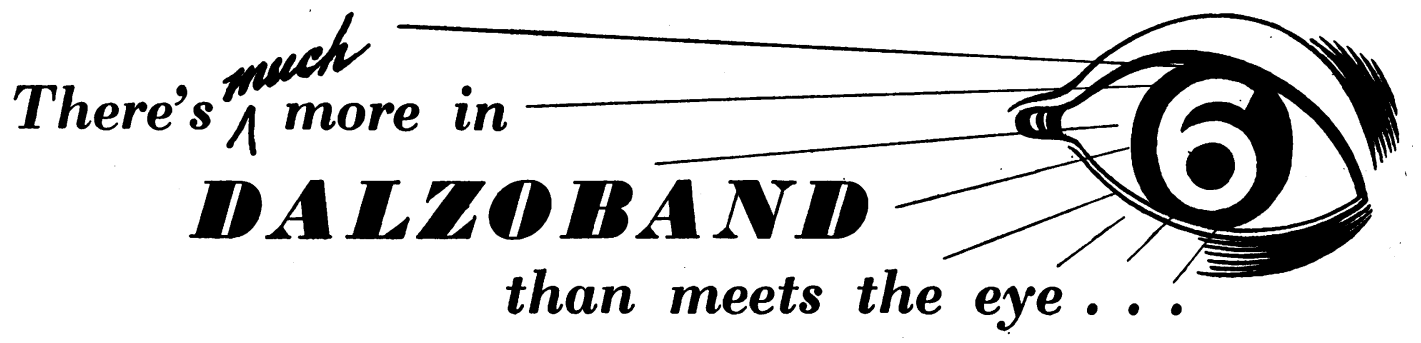

$\star$ Write for test samples and interesting literature-free, please mentioning this publication.

$\star$ Dalzoband Nos. 1,2 , and 3 are accepted for NHS prescriptions.
There are six kinds of Dalzoband, each differing distinctly from another. But all have one thing in common - the traditional Unna's-type zinc oxide base which has proved so dependable. The differences are that each kind has itš own special medicated additives which mark it out for certain well-defined applications covering phlebitis, oedema, eczema - including itching eczema associated with varicose ulcers, chronic ulceration of the legs, chronic dermatitis and burns. Dalzoband keeps moist always.

Dalmas Limited $\star$ Junior Street $\star$ Leicester Telephone 65261

Be safe with Dalzoband a quality-tested product by

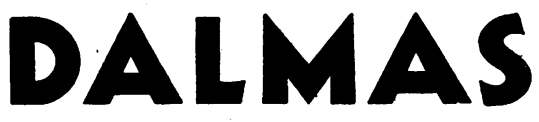

